$2015-6$

\title{
Post-Installed Fiber Optic Pressure Sensors on Subsea Production Risers for Severe Slugging Control
}

\author{
Ammon Eaton \\ Brigham Young University \\ Seyed M. Safdarnejad \\ Brigham Young University \\ John Hedengren \\ Brigham Young University, john.hedengren@byu.edu \\ Kristi Moffat \\ Brigham Young University \\ Casey Hubbell \\ Brigham Young University
}

See next page for additional authors

Follow this and additional works at: https://scholarsarchive.byu.edu/facpub

Part of the Chemical Engineering Commons

\section{BYU ScholarsArchive Citation}

Eaton, Ammon; Safdarnejad, Seyed M.; Hedengren, John; Moffat, Kristi; Hubbell, Casey; Brower, David; and Brower, Alexis, "Post-Installed Fiber Optic Pressure Sensors on Subsea Production Risers for Severe Slugging Control" (2015). Faculty Publications. 1691.

https://scholarsarchive.byu.edu/facpub/1691

This Peer-Reviewed Article is brought to you for free and open access by BYU ScholarsArchive. It has been accepted for inclusion in Faculty Publications by an authorized administrator of BYU ScholarsArchive. For more information, please contact ellen_amatangelo@byu.edu. 


\section{Authors}

Ammon Eaton, Seyed M. Safdarnejad, John Hedengren, Kristi Moffat, Casey Hubbell, David Brower, and Alexis Brower 
OMAE2015-42196

\section{POST-INSTALLED FIBER OPTIC PRESSURE SENSORS ON SUBSEA PRODUCTION RISERS FOR SEVERE SLUGGING CONTROL}

\author{
Ammon N. Eaton \\ Brigham Young University \\ 350 Clyde Building \\ Provo, Utah, 84602 \\ Email: ammon@byu.edu
}

\author{
Seyed Mostafa Safdarnejad \\ Brigham Young University \\ 350 Clyde Building \\ Provo, Utah, 84602 \\ Email: safdarnejad@byu.edu
}

\author{
John D. Hedengren \\ Brigham Young University \\ 350 Clyde Building \\ Provo, Utah, 84602 \\ Email: john.hedengren@byu.edu
}

\author{
Kristie Moffat \\ Brigham Young University \\ 350 Clyde Building \\ Provo, Utah, 84602 \\ Email: kstone10@studentbody.byu.edu
}

\author{
David V. Brower \\ Astro Technology, Inc. \\ 712 Main Street, Suite 3200 \\ Houston, Texas, 77002, USA \\ Email: dbrower@astrotechnology.com
}

\author{
Alexis D. Brower \\ Astro Technology, Inc. \\ 712 Main Street, Suite 3200 \\ Houston, Texas, 77002 \\ Email: abrower@astrotechnology.com
}

\section{ABSTRACT}

Fiber optic sensors have gained increasing use in monitoring offshore structures. The sensors have successfully monitored flowlines, umbilicals, wells, Tension Leg Platform (TLP) tendons, production and drilling risers, and mooring lines. Fiber optic sensors are capable of monitoring strain, temperature, pressure, and vibration. While the success of fiber optic monitoring has been clearly demonstrated, the sensors are now under consideration for automation applications. This paper details the plausibility of using pressure measurements from post-installed fiber Bragg grating (FBG) sensors with Model Predictive Control (MPC) to suppress severe slugging in subsea risers.

Prior control schemes demonstrate that slugging is mitigated using a topside choke valve. The most effective methods use a pressure measurement immediately upstream of the touchdown zone of the riser; however, the majority of production risers do not have pressure sensing at that location. With advances in subsea clamp design and bonding it is now possible to install a non-penetrating FBG sensor to monitor pressure near the touchdown zone without shutting down production. Stabilizing the two phase flow both reduces vibration-induced fatigue and has the potential to allow increased throughput with relaxed topside processing constraints.
MPC predicts and adjusts for disturbances to avoid pressure and flow instability. The performance of the controller is influenced by sensor location, choke valve response time, and riser geometry. This study demonstrates that severe riser slugging is effectively controlled with MPC and a post-installed, non-penetrating FBG sensor.

\section{NOMENCLATURE}

MPC Model predictive control

NMPC Nonlinear model predictive control

PID Proportional, integral, derivative controller

FBG Fiber Bragg grating

DAE Differential and algebraic equations

NLP Nonlinear programming

IPOPT Interior Point Optimizer

$m_{L} \quad$ Total mass of the liquid in the pipeline-riser system

$m_{G 1} \quad$ Mass of gas upstream of the riser section

$m_{G 2} \quad$ Mass of gas in the riser section

$W_{L, \text { in }} \quad$ Mass flow rate of liquid entering the system

$w_{L, \text { out }} \quad$ Mass flow rate of liquid exiting the system

$w_{G, \text { in }} \quad$ Mass flow rate of gas entering the section upstream of the riser

$w_{G 1} \quad$ Mass of gas entering the riser section

$w_{G, o u t}$ Mass of gas exiting the system 
$v_{G 1} \quad$ Velocity of the gas as it enters the riser section

$\rho_{G 1} \quad$ Density of the gas in the section upstream of the upstream

$\hat{\mathrm{A}} \quad$ Cross-sectional area of the gas entering the riser section

$P_{1} \quad$ Pressure at the base of the riser

$P_{2} \quad$ Pressure at the topside of the riser

$P_{0} \quad$ Pressure at the downstream side of the choke valve

$\rho_{L} \quad$ Density of the liquid in the system

$g \quad$ Gravitational constant

$\alpha_{L} \quad$ Average volume fraction of liquid in the riser

$H_{1} \quad$ Liquid height at the riser base at which slugs will begin to form

$\mathrm{H}_{2} \quad$ Total height of the riser

$h_{1} \quad$ Height of the liquid level at the base of the riser

$z \quad$ Valve position

$K_{1} \quad$ A model tuning parameter that adjusts the influence of the choke valve position on mass flow

$\mathrm{K}_{2} \quad$ A model tuning parameter that adjusts the magnitude of the gas velocity at the riser base

$\rho_{T} \quad$ Density of the fluid mixture at the topside of the riser

$W_{\text {out }} \quad$ Total mass flow rate through the choke valve

$W_{\text {in }} \quad$ Total mass flow rate entering the system

$\alpha_{L T} \quad$ Volume liquid fraction in the riser upstream of choke valve

$\alpha_{L T}^{*} \quad$ Volume liquid fraction in the riser without entrainment upstream of the choke valve

$q \quad$ Describes the transition between no entrainment and full entrainment

$n \quad$ A model tuning parameter that adjusts the slope of the entrainment transition

$\tau_{p} \quad$ Process time constant

$K_{p} \quad$ Process gain

$\Theta_{m} \quad$ Measurement time delay

D Diameter of the riser

\section{INTRODUCTION}

Two phase flow in pipelines can lead to an unstable flow regime known as slugging. When slugging with large amplitudes of pressure and flow occurs in subsea oil well production risers it is termed severe slugging. The undesired oscillations caused by severe slugging can slow oil and gas production, and cause accelerated wear to production equipment. Many technologies have been developed to control the effects of slugging including changing the design of separation equipment to better accommodate the slugs, the addition of a large topside holding tank to 'catch' the slugs, and subsea phase separators that separate the liquid from the gas near the wellhead. These methods are often expensive or sub-optimal solutions [1]. Another way to mitigate the effects of severe slugging is through a choke valve at the topside of the production riser. The valve can be used by a controller to dampen the oscillations caused by slugging. This inexpensive solution was first reported as successful in 1990 [2] and has since been studied extensively.
Several controllers have been designed for slugging suppression including PI [2], cascaded PID [3], Model Predictive Control (MPC) [4], neural networks [5], and gain-scheduling Internal Model Control (IMC) [6]. These controllers generally attempt to control the pressure at the base of the riser. Many of the prior studies assume that pressure is measured or estimated at the riser touchdown zone where the slugs are generated. However, most production risers do not have a pressure measurement at the riser base and slugging models may not be able to accurately estimate the necessary states. Without a pressure measurement in this area it is difficult to create an effective feedback control loop. However, recent advances in post-installed fiber optic clamp design now allow a pressure measurement near this location [8]. This paper details the plausibility of using a non-penetrating, post-installed pressure measurement at a production riser base.

\section{MODEL}

The slugging process was modelled in this study using a simplified three state model that was developed by Storkaas [9]. While other higher order slugging models exist, the three-state model is simple and sufficiently accurate for control purposes. The model consists of an L-shaped riser as depicted in Fig. 2. The major assumptions of the model are:

1) The liquid velocity in the section upstream of the riser is constant.

2) The gas volume in the upstream section is constant.

3) The liquid mass holdup in the riser section is described by one dynamic state $\left(m_{L}\right)$.

4) The gas mass holdup in the riser is described by one dynamic state $\left(m_{G 2}\right)$ and is related to the dynamic state of the gas mass in the upstream section $\left(m_{G 1}\right)$ by a pressure-flow equation of the low-point of the riser.

5) The gas behaves ideally.

6) There is a static pressure balance between the upstream pressure $\left(P_{1}\right)$ and the topside pressure $\left(P_{2}\right)$.

7) The system is at a constant temperature.

Refer to [9] for a complete description of the model assumptions.

The dynamic states in the model are expressed with Eqn. (1) as a liquid mass balance, Eqn. (2) as a gas mass balance upstream of the riser, and Eqn. (3) as a gas mass balance in the riser section.

$$
\begin{aligned}
& \frac{d m_{L}}{d t}=w_{L, \text { in }}-w_{L, \text { out }} \\
& \frac{d m_{G 1}}{d t}=w_{G, \text { in }}-w_{G 1} \\
& \frac{d m_{G 2}}{d t}=w_{G 1}-w_{G, \text { out }}
\end{aligned}
$$


Here, $m_{L}$ is the mass of the liquid, $m_{G 1}$ is the mass of the gas in the section upstream of the riser, and $m_{G 2}$ is the mass of the gas in the riser. The variable $w$ in its various forms is the mass flow rate with subscripts $\mathrm{L}$ for liquid and $\mathrm{G}$ for gas. The mass flow of gas upstream of the risers given by Eqn. (4).

$$
w_{G 1}=v_{G 1} \rho_{G 1} \hat{\mathrm{A}}
$$

Here $\hat{A}$ is the cross-sectional area of the flowing gas at the riser base, $\rho_{G 1}$ is the density of the gas in the upstream section of the system, and $v_{G 1}$ is the velocity of the gas at the low point of the riser. This velocity of the gas in the section upstream of the riser is described by Eqn. (5).

$$
v_{G 1}=K_{2}\left(\frac{H_{1}-h_{1}}{H_{1}}\right) \sqrt{\frac{P_{1}-P_{2}-\rho_{L} g \alpha_{L} H_{2}}{\rho_{G 1}}}
$$

In this case, $K_{2}$ is a multiplicative factor that adjusts the magnitude of the gas flow, $H_{1}$ is the critical liquid level at the low-point of the riser, $h_{1}$ is the actual liquid level in the upstream of the riser, $P_{1}$ is the pressure in the section upstream of the riser, $P_{2}$ is the pressure in the riser, $\rho_{L}$ is the density of the liquid, $g$ is the gravitational constant, $\alpha_{L}$ is the average fraction of liquid in the riser, and $\mathrm{H}_{2}$ is the height of the riser. The valve was modeled using a simplified equation, Eqn. (6).

$$
w_{\text {out }}=K_{1} z \sqrt{\left(P_{2}-P_{0}\right) \rho_{T}}
$$

Here $w_{\text {out }}$ is the total mass flow rate exiting the valve, $K_{1}$ is a model tuning parameter, $z$ is the valve percent opening, $\rho_{T}$ is the average density of the fluid flowing through the valve, and $\left(P_{2}-P_{0}\right)$ is the pressure drop across the valve. Additionally, the fluid distribution in the riser is modelled using Eqn. (7).

$$
\alpha_{L T}=\alpha_{L T}^{*}+\frac{q^{n}}{1+q^{n}}\left(\alpha_{L}-\alpha_{L T}^{*}\right)
$$

$\boldsymbol{\alpha}_{\boldsymbol{L} T}$ is the liquid fraction in the section immediately upstream of the control valve, $\boldsymbol{\alpha}_{\boldsymbol{L} T}^{*}$ is the liquid fraction without entrainment, $\boldsymbol{q}$ is a parameter that describes the transition between the full entrainment and no entrainment. $\boldsymbol{n}$ is a tuning constant that changes the slope of the transition. The equations presented here are the major equations used to define the model riser; for a complete description refer to [9].

One of the limitations of this model is that the mass flow rates entering the system $\left(w_{L, \text { in }}, w_{G, \text { in }}\right)$ are constant. This attribute constrains the production to these values, and does not allow the controllers to maximize production. Fig. 1 shows the open loop response of the riser base pressure, topside pressure, and mass flow rate out of the system as a function of valve percent open. When the valve is $10 \%$ open, the slugs are effectively dampened.
The minimum valve position where slugging occurs is $13 \%$ open [9].
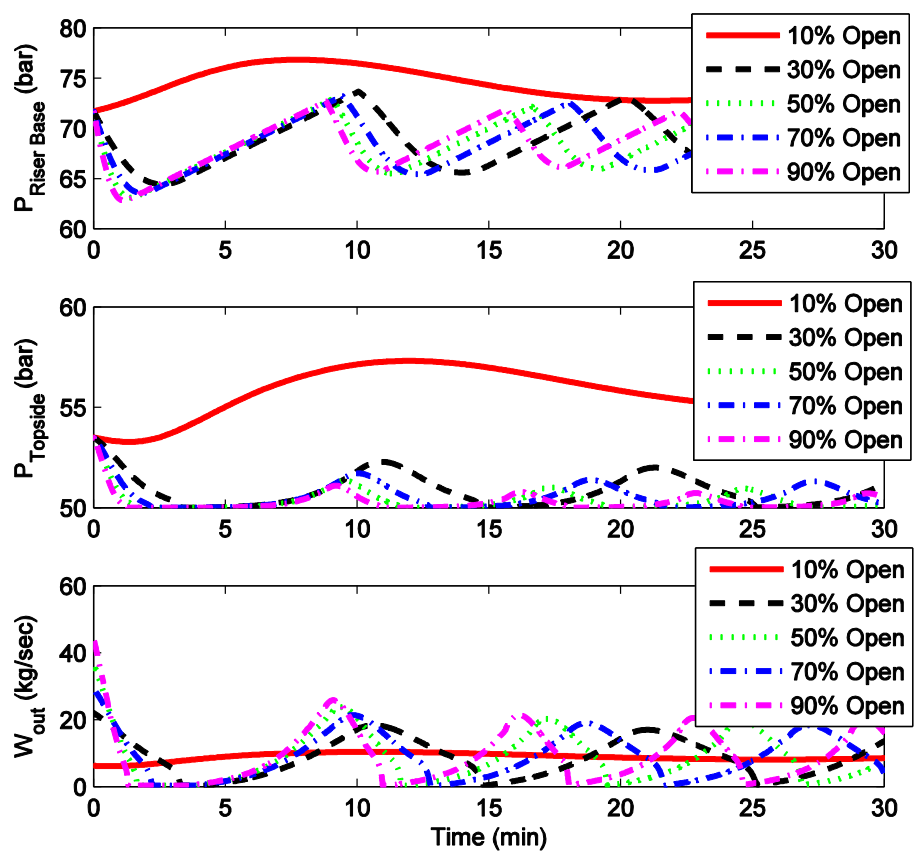

Figure 1. OPEN LOOP RESPONSE OF THE RISER BASE PRESSURE, TOPSIDE PRESSURE, AND MASS FLOW RATE OUT OF THE RISER TO VALVE PERCENT OPEN.

\section{CONTROLLERS}

Two controllers were used in this study, a Model Predictive Controller (MPC) and a traditional PID controller.

\section{MPC Controller}

One of the advantages of MPC over traditional controllers is its ability to predict future disturbances and respond to them before they affect the process. MPC uses a process model to optimize the controller's output over a specified time horizon. The benefits of MPC come at the expense increased computation time. The model used for optimization in this controller was a modified first order plus dead-time (FOPDT) model shown in Eqn. (8).

$$
\tau_{p} \frac{\mathrm{d} P_{1}}{\mathrm{dt}}=-\left(P_{1}-P_{\text {ref }}\right)+K_{p}\left(z-z_{r e f}\right)
$$

Here, $\tau_{p}$ is the process time constant, $P_{\text {ref }}$ is a reference pressure, $z_{\text {ref }}$ is a reference valve position, and $K_{p}$ is the process gain. The MPC controller for this project was created in the APMonitor modeling language. APMonitor uses collocation methods to convert the model's differential and algebraic 
equations (DAEs) into a nonlinear programming (NLP) optimization problem [10]. The NLP problem is then given to an active set solver, APOPT, to find the optimal controller output. The controller output is the valve position $(z)$, and the inputs are the constant mass flow rates of liquid $\left(w_{L, i n}\right)$ and gas $\left(w_{G, i n}\right)$ into the pipeline. It also receives a pressure measurement from the fiber optic sensors at the base of the riser $\left(P_{1}\right)$ and the topside $\left(P_{2}\right)$. The MPC controller uses an $\ell_{1}$-norm objective function in the optimization routine. This allows the controller to use a deadband set point instead of just a single value as with the standard $\ell_{2}$-norm objective function. This dead-band defines the range of acceptable values for the controlled variable, which in this case is the riser base pressure $\left(P_{1}\right)$. This range of acceptable values gives the controller greater flexibility in arriving at an optimal solution. The $\ell_{1}$-norm objective function has also demonstrated better rejection of measurement noise, outliers, and drift than a squared error objective function [10].

\section{PID Controller}

The PID controller used in this study was a modified version of the PID controller created by [9]. The modifications include the addition of anti-reset windup and deletion of rate limiting on the valve position. The derivative term was set equal to zero. After these modifications were made the controller was appropriately tuned and included in the study as a benchmark controller.

\section{SIMULATION}

The riser slugging is simulated in $\mathrm{MATLAB}^{\circledR}$ and Simulink $^{\circledR}$. The pipeline-riser system is simulated as a 0.12 meter (4.75 inch) diameter flowline with 4300 meters ( 2.67 miles) of line upstream of the riser. The riser is 300 meters (984 feet) deep and runs for 100 meters (328 feet) to the topside receiving facilities. The angle of incline at the base of the riser $(\Theta)$ is 1.57 degrees (see Fig. 2).

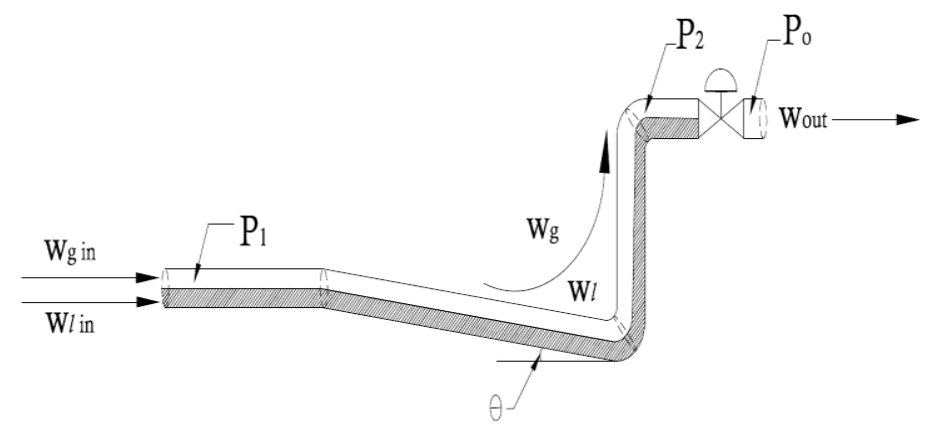

Figure 2. ILLUSTRATION OF THE L-SHAPED RISER SIMULATED IN THIS STUDY.
The gas and liquid mass flow rates entering the system are $0.36 \mathrm{~kg} / \mathrm{s}\left(w_{G, i n}\right)$ and $8.64 \mathrm{~kg} / \mathrm{s}\left(w_{L, i n}\right)$ respectively. The system temperature is assumed constant at $308 \mathrm{~K}$. The molecular weight of the gas is $35 \mathrm{~kg} / \mathrm{kmol}$, and the liquid is pure oil with a density of $750 \mathrm{~kg} / \mathrm{m}^{3}$. Finally, the pressure of the topside receiver is assumed constant at 50 bar. The pressure at the riser base is used as the controlled variable (CV) and the valve position is the manipulated variable (MV) for the simulation. When the pressure oscillations are dampened, the flow will also stabilize. The addition of a pressure measurement at the riser base completes the feedback control loop. The Simulink ${ }^{\circledR}$ diagram of the process is found in Eqn. (3).

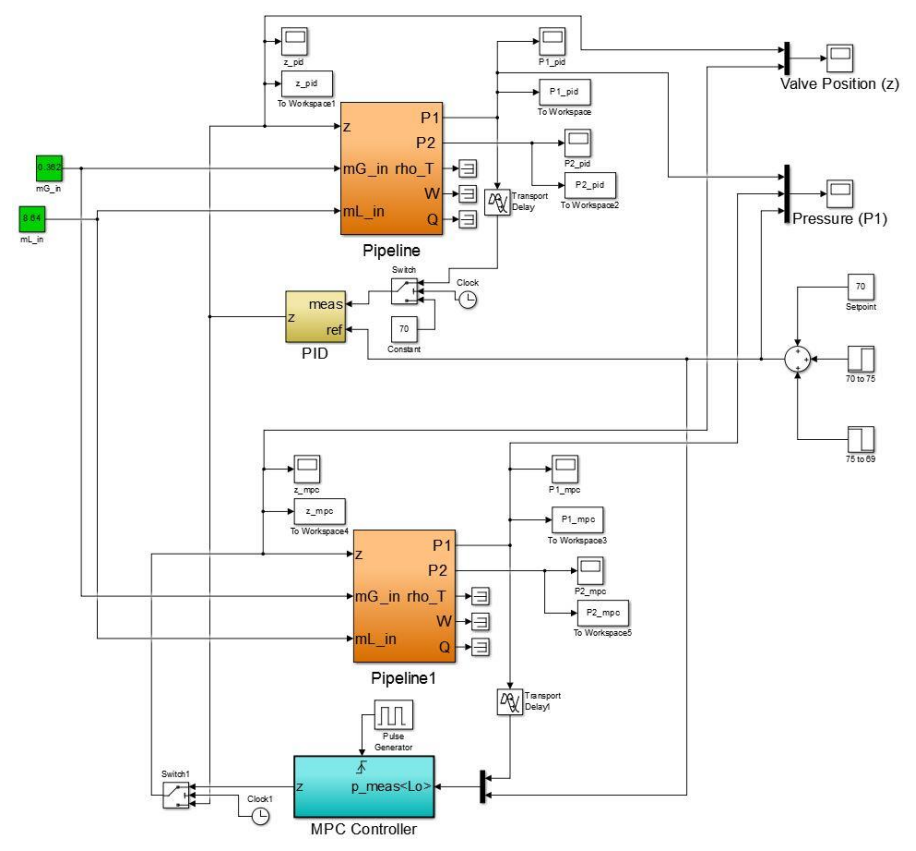

Figure 3. THE SIMULINK DIAGRAM OF THE SLUGGING CONTROLLERS USED IN THE SIMULATION. THE LOWER BLOCK IS THE MPC CONTROLLER.

\section{SIMULATION RESULTS}

In this simulation, the controllers were activated at 33 minutes. The set point is 70 bar until 50 minutes when it moves to 75 bar. At 67 minutes it moves again to 69 bar (see Fig. 4). The controller output and the process response are shown in Fig. 4. 

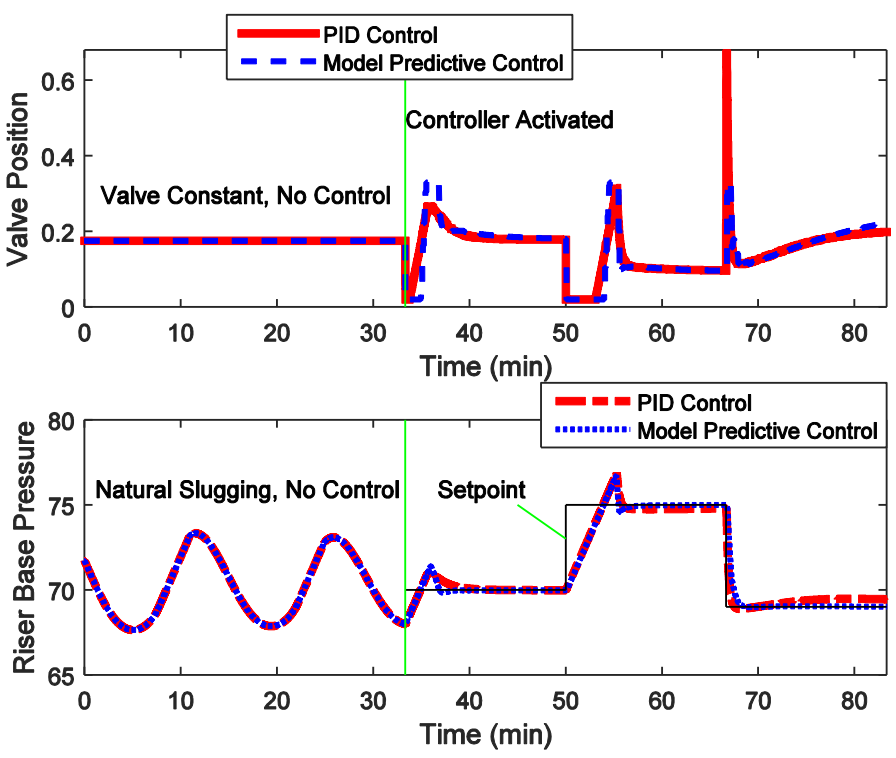

Figure 4. RESULTS OF THE RISER SLUGGING SIMULATION. THE TOP GRAPH IS THE VALVE POSITION (MV) AND THE LOWER GRAPH IS THE RISER BASE PRESSURE (CV). THE PID CONTROLLER IS THE SOLID LINE (RED) WHILE THE MPC IS THE DOTTED LINE (BLUE). THE CONTROLLER WAS ACTIVATED AT 33 MINUTES AND THE SET POINT WAS CHANGED AT 50 MINUTES AND AT 67 MINUTES.

Figure 4 demonstrates the superior performance of the MPC controller over the PID controller. While the rise times of the MPC and PID controllers are identical, the MPC controller achieves the set point quickly, while the PID controller has minor persistent offset.

\section{MEASUREMENT POSITION AND TIME DELAY}

The effect of clamp position, and therefore pressure measurement delay, on riser slugging control was explored. If the pressure measurement location is at the riser base, then there will be no time delay in the measurement. However, if the position of the sensor clamp is moved vertically up the riser then the time that the controller has to adjust to the slugs will decrease. If a pressure measurement is only available on the topside then the measurement time delay will be at a maximum and the controller will not have sufficient time to effectively control the slug. The theoretical time delay was calculated using Eqn. (9).

$$
\theta_{\mathrm{m}}=\frac{H_{2} \rho_{L} D^{2}}{4 W_{i n}}
$$

In this equation, $\theta_{\mathrm{m}}$ is the measurement time delay, $D$ is the riser diameter, and $W_{\text {in }}$ is the total mass flow of the system. All other variables are previously defined. The liquid density was used in this calculation because it will result in the maximum possible time delay. The actual mixture density will be less and so will the delay. Using the liquid density constitutes the worst case scenario.

Applying Eqn. (9) to the simulated case gives a measurement time delay of 105 seconds. This represents what the delay would be if the topside pressure measurement were the only measurement used in the control loop. Figure 5 shows the PID controller response to 105 seconds of time delay.
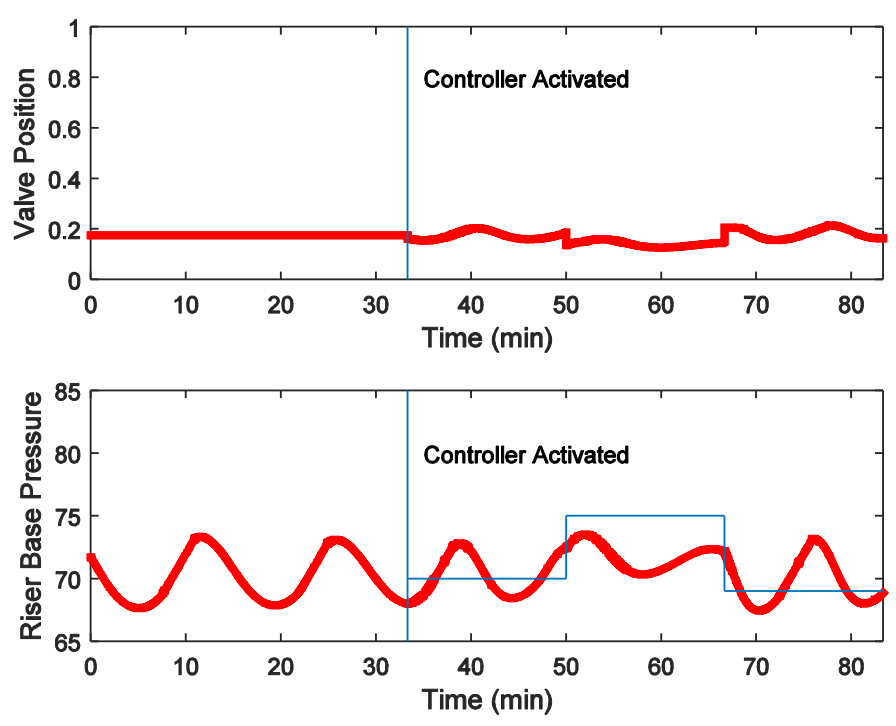

Figure 5. PID CONTROLLER RESPONSE WITH ONLY A TOPSIDE PRESSURE MEASUREMENT (105 SECOND TIME DELAY). THE TOP PLOT SHOWS VALVE POSITION, AND THE BOTTOM PLOT SHOWS RISER BASE PRESSURE. THE CONTROLLER IS ACTIVATED AT 33 MINUTES. THE SET POINT CHANGES FROM 70 BAR TO 75 BAR AT 50 MINUTES, THEN TO 69 BAR AT 67 MINUTES.

This demonstrates the controller performance when only a topside pressure measurement is available in the control loop. Additionally, the time delay was changed to simulate the point at which the PID controller could no longer control the process. Fig. 6 shows the PID controller response to varying measurement time delay. 

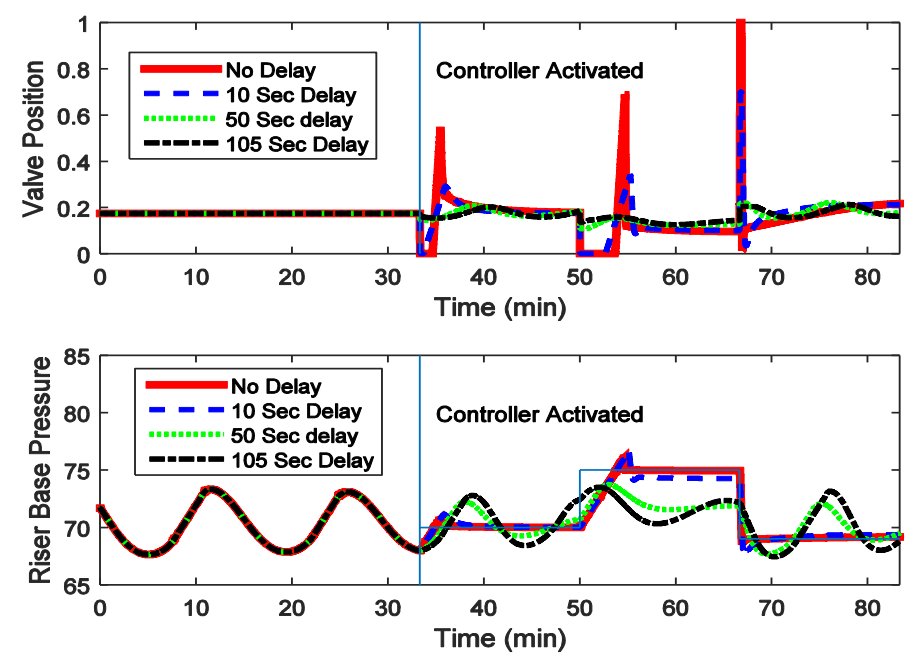

Figure 6. PID CONTROLLER RESPONSE WITH VARYING MEASUREMENT TIME DELAY. THE TOP PLOT SHOWS VALVE POSITION, AND THE BOTTOM PLOT SHOWS RISER BASE PRESSURE. THE CONTROLLER IS ACTIVATED AT 33 MINUTES. THE SET POINT CHANGES FROM 70 BAR TO 75 BAR AT 50 MINUTES, THEN TO 69 BAR AT 67 MINUTES.

With 50 seconds of time delay, corresponding to 167 meters of riser, the controller is unable to dampen the oscillations. This is the maximum riser height that this controller can regulate using only topside pressure measurements.

\section{POST-INSTALLED FIBER OPTIC SENSOR CLAMP}

This work builds upon prior work on the design and deployment of fiber optic subsea sensing of temperature, pressure, vibration, strain, and flow assurance [8]. The postinstalled and non-penetrating sensor can be installed by a diver or remotely operated vehicle (ROV), depending on the target depth. A pressure measurement at the riser base eliminates the need for estimators in the control scheme and reduces computation time. With advances in subsea fiber optic monitoring and post-installed clamp design, virtually any riser can be fitted with pressure measurements at the base of the riser. There are two types of clamps that can be used to secure the optical fiber Bragg grating (FBG) sensors to the pipe. The adhesive clamp and the friction clamp are shown in Fig. 7.
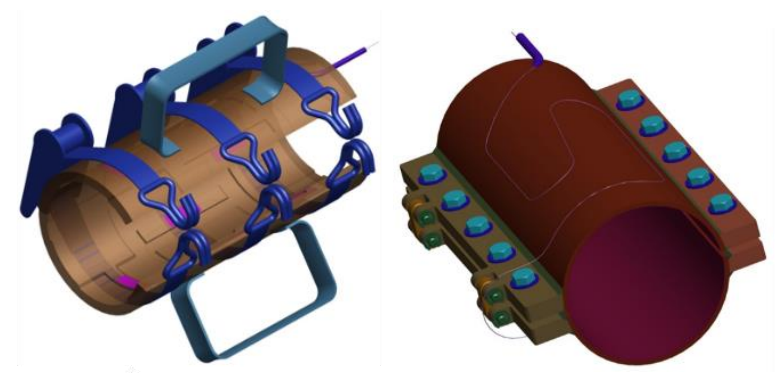

Figure 7. ADHESIVE CLAMP (LEFT) AND FRICTION CLAMP (RIGHT) FOR INSTALLING A PRESSURE SENSOR AT THE RISER TOUCHDOWN ZONE.

\section{CORROSION, DRIFTING, AND MEASUREMENT DELAY}

For the controller to accurately regulate the choke valve and suppress slugging, it must be able to quickly interpret any change in pressure in the pipe. If there is a time delay between actual pressure change and the measurement by the FBG sensor, it could potentially cause the controller to become unstable. Therefore, the relationship between pressure change and pipe wall strain is explored. There are two principles that govern the change of strain. First, strain will change instantaneously on the inside of the pipe surface following fluctuation in pressure when the steel is modeled as linearly elastic [11]. This strain will then propagate through the thickness of the material at the longitudinal speed of sound. This was measured to be 16,600 feet per second in 1020 steel [12]. Assuming a 16 inch Schedule 80 pipe, the time required to detect a change in pressure is 4.23 microseconds. Compared to the average speeds of fluid flowing through the pipe, this amount of time is negligible. Therefore, the pressure sensor will return information to the controller fast enough to promptly adjust the choke valve opening. Recalibration of the pressure sensor will become necessary once certain strain-inducing mechanisms become significant. Creep will not need to be considered since the pipe is operating at subsea temperatures [13]. However, corrosion on the inside of the pipe will thin the pipe wall, increasing strain and causing the 
calibration curve to drift. A simulation where 0.01 inches of steel have corroded was analyzed and the results are shown in Fig. 8.

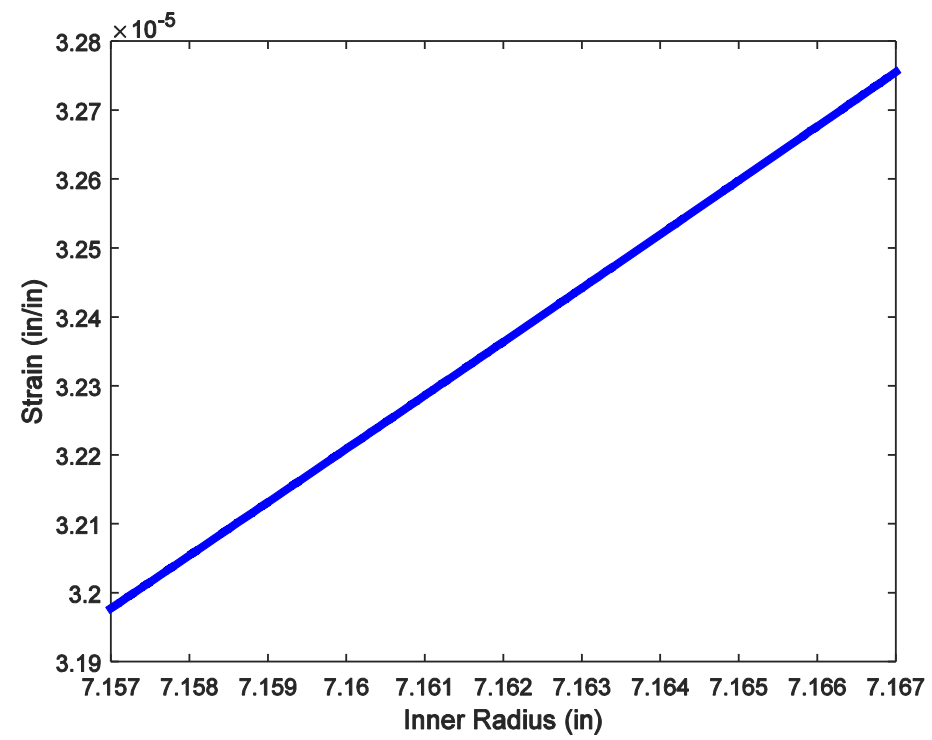

Figure 8. STRAIN VS. PIPE WALL THICKNESS IN SIMULATED CORROSION OF 0.01 INCHES OF THE INSIDE OF THE PIPE, NOTE: THE RELATIONSHIP APPEARS LINEAR ON THIS SCALE, BUT IS ACTUALLY NONLINEAR.

The method of calculating strain was based on contributions from both radial and tangential stresses [14]. Over this amount of corrosion, the strain rises by $2.6 \%$ as seen in Fig. 8 . Therefore, depending on the rate of corrosion within the pipe, the pressure sensor will need to be periodically re-calibrated into order to accurately measure the pressure.

\section{CONCLUSION}

The plausibility of using post-installed, non-penetrating fiber optic sensors for controlling severe riser slugging was detailed. Recent advances in clamp design allow these pressure sensors to be post-installed on virtually any riser. The effect of the measurement time delay was investigated as dictated by the pressure device location. For this simulated system, a traditional PID controller with topside-only pressure measurement performs poorly when the riser height exceeds 167 meters. In contrast, a PID controller with a pressure measurement at the touchdown zone of the riser can successfully control slugging. A MPC controller was compared to this PID controller and found to provide superior control of slugging. In addition to the predictive qualities of the MPC controller, it also utilized an 11norm objective function which will allow for better noise, drift and outlier rejection in the field. Additionally, the corrosion effects on the sensor were simulated and as corrosion occurs the sensors will need to be recalibrated.

\section{ACKNOWLEDGMENTS}

Several leading oil and gas companies have provided technical and financial leadership in the Clear Gulf Joint Industry Project (JIP). Founded in the fall of 2010, Clear Gulf JIP supports extensive testing and further development of advanced monitoring solutions, with critical input coming from experts at NASA as well as leaders within the industry. The project's technical steering committee includes representatives from participating companies. Participants are part of a high-profile effort to enhance safety and reduce environmental risk. The Clear Gulf steering committee will work with the Energy and Commerce Committee of the U.S. House of Representatives, the Bureau of Offshore Energy Management (BOEM), and the Bureau of Safety and Environmental Enforcement to ensure that systems support operators in meeting new offshore regulations.

\section{REFERENCES}

1. Godhavn, J.-M., M.P. Fard, and P.H. Fuchs, New slug control strategies, tuning rules and experimental results. Journal of Process Control, 2005. 15(5): p. 547557.

2. Hedne, P. and H. Linga, Suppression of terrain slugging with automatic and manual riser choking, in ASME Winter Annual Meeting. 1990: Dallas, Texas.

3. Skofteland, J.G. and J.-M. Godhavn, Supression of Slugs in Mulitphase Flow Lines by Active Use of Topside Choke - Field Experience and Experimental Results, in 11th BHR Group Multiphase Production International Conference. 2003: San Remo, Italy.

4. DiMelio, F., et al., Model-based Control of Slugging: Advances and Challenges, in 2012 IFAC Workshop on Automatic Control in Offshore Oil and Gas Production. 2012: Trondheim, Norway.

5. Eslamloueyan, R. and E. Hosseinzadeh, Using Neural Network Predictive Control for Riser-Slugging Suppression. Chemical Product and Process Modeling, 2009. 4(4).

6. Jahanshahi, E. and S. Skogestad, Comparsion Between Nonlinear Model-based Controllers and Gainscheduling INternal Model Control Based on Identified Model, in 52nd IEEE Conference on Decision and Control. 2013: Florence, Italy.

7. Monteiro, P.C.C., et al., Study of Slug Control Techniues in Pipeline Systems, in 33rd International Conference on Ocean, Offshore and Arctivc Engineering OMAE. 2014: San Francisco, California, USA.

8. Asgharzadeh Shishivan, R., et al., New Advances in Post-Installed Subsea Monitoring Systems for Structural and Flow Assurance Evaluation, in 33rd International Conference on Ocean, Offshore and Arctic Engineering OMAE. 2014: San Francisco, California, USA.

9. Storkaas, E., Stabilizing Control and Controllability: Control Solutions to Avoid Slug Flow in Pipeline-Riser Systems, in Chemical Engineering. 2005, Norwegian 
University of Science and Technology: Trondheim, Norway.

10. Hedengren, J.D., et al., Nonlinear modeling, estimation and predictive control in APMonitor. Computers \& Chemical Engineering, 2014. 70: p. 133-148.

11. Bower, A.F., Applied Mechanics of Solids. 2010: Boca Raton.

12. Santosham, T.V. and H. Ramsey, The Dynamic Elastic Behavior of Mild Steel, Aluminum, and Copper as Observed in wave Propagation Tests. International Journal of Mechanical Sciences, 1969. 11(9): p. 751765.

13. Nie, D.-F., et al., Room Temperature Creep and Its Effects on Flow Stress in X70 Pipeline Steel. Material Letters, 2008. 62(1): p. 51-53.

14. Budynas, R.G., J.K. Nisbett, and J.E. Shigley, Stress in Pressurized Cylinders. Shigley's Mechanical Engineering Design. 9th Edition. 2011, New York: McGraw-Hill. 